\title{
Psycho-Emotional State of Students with Special Educational Learning Needs
}

\author{
Toxanbaeva Nurgul ${ }^{1}$, Bibigul Almukhambetova², Zabira Madaliyeva1, Zhubanazarova \\ Nazirash ${ }^{1}$, Baimoldina Laura Orazbekovna ${ }^{1}$ and Toxanbayeva Nazgul Bakytkyzy ${ }^{1}$ \\ ${ }^{1}$ Department of General and Applied Psychology at Al-Farabi Kazakh National University, Kazakhstan \\ ${ }^{2}$ Zhetysu State University, I. Zhansugurov, Taldykorgan, Kazakhstan
}

\begin{abstract}
This article is devoted to the study of the psycho-emotional state of students with special educational needs in education. The primary objective of the study was to study the theoretical views of domestic and foreign researchers on the psycho-emotional state and manifestation of anxiety; to conduct a theoretical analysis of the relationship of stress and the learning process; to clarify the manifestation of anxiety among students with special educational needs of our University in the learning process. The hypothesis of the study was as follows: for students with special educational needs, the learning process is accompanied by a manifestation of anxiety and harms their psycho-emotional state. The results obtained in the course of the study led to the conclusion that students with special educational needs in the learning process involve a range of factors that determine the behavioural reactions of frustrating nature. And that is why, because of the mismatch of opportunities, priorities, there is an increase in the normative level of anxiety, which affects their overall psycho-emotional state.
\end{abstract}

Keywords: Anxiety, psychological characteristics of students with special educational needs, the learning process.

\section{INTRODUCTION}

The problem of emotions, mental and physical health of persons with special educational needs, emotional security of the educational environment of the University is now becoming more and more urgent. Researchers are beginning to pay attention not only to the academic performance of students with SEN but also what emotions they experience when studying at universities. This corresponds to the General humanisation of the educational process, which is currently taking place. Psycho-emotional States - a particular form of mental States of a person with a predominance of emotional response by type of dominant. In other words, it is an emotional reaction of a person to some action, situation or response of a person. All human emotions can be distinguished and classified by the quality of experience. American psychologist $\mathrm{K}$. Isard identified ten qualitatively different" fundamental " emotions: interest-excitement, joy, surprise, grief - suffering, anger - rage, disgust disgust, contempt - neglect, fear - horror, shame shyness, guilt - remorse. The first three he refers to the positive, the other seven - to the negative. Thus, a person can manifest positive, negative psychoemotional States, which revealed in the form of anxiety. The problem of emotions in students with special educational needs is not fully covered in modern psychological science. About how the educational

Address correspondence to this article at the Kazakh State National University of Al-Farabi, Almaty, Kazakhstan; Tel: +77073851878;

E-mail: zhanat_2006@mail.ru process affects the state of students, what directs the person who came to higher education, what she feels and what emotions move her. But the knowledge of the psycho-emotional state of students with special educational needs would give the opportunity to structure the educational process properly. At the time, L. S. Vygotsky in the theory of the unity of the age patterns of normal and abnormal development of emotion indicated that there is an enormous potential healthy instinct have an abnormal child, the disclosure of which is necessary to its integration in life, and the goal of integration should be the organization of appropriate conditions. The current statistics show us very disappointing data, showing an increase every year in the number of children with special educational needs. The analysis of the international experience of inclusion of children with special educational needs in the overall learning process shows that, despite the appearance of their ability to communicate with their peers, to be included in the same activities (setting different tasks), to participate in joint projects, group decision-making, etc., children with special educational needs, emotional comfort, a sense of cheerfulness accompanied with anxiety. Of all the cognitive processes, the emotional aspect is the basic one when adapting a person to society, when including him in the educational process, because the subjective fulfilment of various social role functions, transforms the person and the world around him. And it is the psychoemotional state, as noted by the researchers [1-5], that complicates the adaptation period in the learning process in children with special educational needs. 
Psycho-emotional background, accompanied by increased anxiety and the psyche of the student, are interdependent factors affecting the following mental areas: emotional, intellectual, motivational, communication.

Student age is a period of serious psychological changes, beginning with the formation of self-esteem and ending with the maturation of a sense of trust in the world. In this regard, very often many young people who keep up (even ahead) in the intellectual development of their healthy peers do not live a full life, they do not form sufficient motivation and communication skills, resulting in their increased anxiety, expressed either in isolation or in isolation from people, [6,7]. In our research, we consider the psychoemotional state as the experience of emotional discomfort, premonition, and expectation of not wellbeing, danger. At the same time, it is known that the high educational load massively exposes students to stress, which in turn can also lead them to the manifestation of anxiety. These facts support the relevance of our work, as we conducted the study in the context of the educational orientation of students with special educational needs.

Thus, we conducted an empirical study of the psycho-emotional state and the level of anxiety in students with special educational needs in the learning process at our University. A data Bank on students with special educational needs was formed as well. The study involved 25 students with special educational needs of different areas of training. This sample was heterogeneous (men and women). The group included subjects aged 18-21 years with disorders of the musculoskeletal system 13 students, visual impairment 6 , hearing impairment 4 , speech disorders 2 students. The study was conducted from 22 to 27 October.

The subject of the study is the study of the psychoemotional state and the manifestation of anxiety in students with special educational needs in the learning process.

The study aimed to study the psycho-emotional state and anxiety in students with special educational needs in the learning process.

The primary objective of the study was to study the theoretical views of domestic and foreign researchers on the subjects of psycho-emotional state and anxiety; to conduct a theoretical analysis of the relationship of anxiety and the learning process; to clarify the manifestations of anxiety among students with special educational needs of our University in the learning process.

The object of the study is the learning process and the emotional sphere of the student.

Hypothesis: for students with special educational needs, the learning process is accompanied by the manifestation of anxiety and has a negative impact on their educational and cognitive activities. The methodological basis of our study was the concept of anxiety Z. Freud, K. Horney, K. Isarda, V. M. Astapova. $M$. Parishioners and others.

\section{MATERIALS AND METHODS}

To conduct the research, we used the following methods: analysis, survey, methods of quantitative analysis, methods of studying the level and nature of anxiety Phillips, methods of analysing the level and nature of anxiety Spielberger.

The research was conducted on the basis of Zhetysu State University named after I. Zhansugurov. In order to identify the degree of satisfaction with the quality of the educational process in our University, a survey of students with special educational needs was conducted.

\section{RESULTS}

Analysing the data obtained from the survey, we obtained the following results: the question " are you Satisfied with getting higher education in your University?": "Yes" answered-100\% of respondents, it allows to characterise the learning process, in General, the process of preparing them as future professionals to life, in this situation, for them positive. "What is necessary for the effectiveness of your higher education?"72.7\% of students with OOP indicated interest in the chosen speciality, which indicates their need for training and professional activities, selfdevelopment, self-knowledge. This also indicates the motivational readiness of persons with SEN for professional development. On the same question, $27.3 \%$ of respondents noted the need to guarantee their further employment; this fact confirms the complexity of competition for students in the labour market for health reasons and the possibility of their professional self-realisation. To the question "what form of higher education would be convenient for you?" $100 \%$ of respondents named full-time education, while $60 \%$ of students in the sample have disorders of 


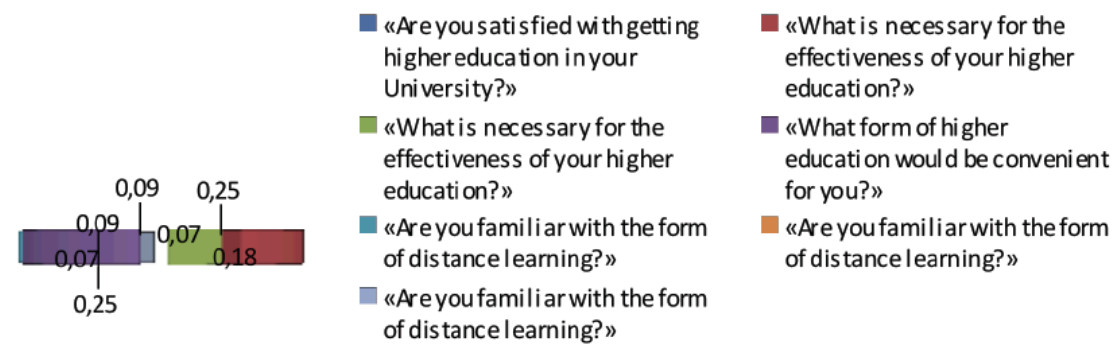

Diagram 1: Results of the survey of students with special educational needs.

the musculoskeletal system. Answers to the question, " are you Familiar with the form of distance learning?" there were the following: $27.2 \%$ positive, $36.4 \%$ said" no "and" partially familiar " $36.4 \%$ of respondents. About functioning and availability of the modern form of training realised generally by application of information and telecommunication networks, the bulk of respondents in ignorance that raises a question of the need of orientation of all subjects of educational space in this area.

The data obtained are shown in Diagram 1.

To identify the factors of anxiety that affect the emotional state, the learning process of students, relationships with society, the Phillips test was conducted. A questionnaire of Phillips refers to the standardised psychodiagnostic methods, gives the opportunity to evaluate unpleasant feelings associated with different areas of training activities. The purpose of the methodology in the study of the level and nature of anxiety associated with learning activities. The questionnaire consists of 58 questions, which were proposed in our case in writing.
According to the results of the study, as can be seen from Table 1, the increased and high level on the scale of "General anxiety" have 10 students, i.e. $40 \%$ of the subjects. Such indicators indicate the tendency of the individual to experience the anxiety of different levels of tension in the learning process, in interaction with others. The normal level of anxiety has 15 students with SEN, $60 \%$ of the subjects. For them, training at the University and the requirements of the University correspond to their capabilities, and this creates a picture of normal life, professional development in the educational process, the establishment of favourable relationships with others. Quite a large part of the subjects $72 \%$ do not experience social stress. This is an excellent indicator of their positive and prosperous relationship with society. The percentage of students experiencing stress at an elevated level of $20 \%$ and a high level of $8 \%$. Such data show a tense, negatively coloured emotional state, which is a prerequisite for the development of anxiety as a fact of social stress. The frustration factor of the need for success shows the following: $68 \%$ have a normal level; this suggests that

Table 1: Distribution of Subjects According to the Level and Nature of Anxiety Associated with Educational Activities

\begin{tabular}{|c|c|c|c|c|c|c|c|}
\hline \multirow[b]{2}{*}{ № } & \multirow[b]{2}{*}{ Factors } & \multicolumn{2}{|c|}{ Normal level } & \multicolumn{2}{|c|}{ Elevated level } & \multicolumn{2}{|c|}{ High level } \\
\hline & & $\begin{array}{c}\text { number of } \\
\text { persons }\end{array}$ & $\%$ & $\begin{array}{c}\text { number of } \\
\text { persons }\end{array}$ & $\%$ & $\begin{array}{c}\text { number of } \\
\text { persons }\end{array}$ & $\%$ \\
\hline 1 & General anxiety & 15 & 60 & 8 & 32 & 2 & 8 \\
\hline 2 & The experience of social stress & 18 & 72 & 5 & 20 & 2 & 8 \\
\hline 3 & Frustration of the need to succeed & 17 & 68 & 7 & 28 & 1 & 4 \\
\hline 4 & Fear of self-expression & 7 & 28 & 18 & 72 & 0 & 0 \\
\hline 5 & Fear of knowledge testing situation & 15 & 60 & 9 & 36 & 1 & 4 \\
\hline 6 & $\begin{array}{c}\text { Fear of not meeting the expectations of } \\
\text { others }\end{array}$ & 12 & 52 & 11 & 44 & 2 & 8 \\
\hline 7 & Low physiological resistance to stress & 16 & 64 & 5 & 20 & 4 & 16 \\
\hline 8 & Problems and fears in relations with teachers & 17 & 68 & 6 & 24 & 2 & 8 \\
\hline
\end{tabular}


most of the subjects are ready for the learning process and do not feel fear. $28 \%$ increased, and $4 \%$ of the subjects have a high level of this factor, which is evidence of negative emotions. But, at the same time, $72 \%$ of the subjects have increased levels of fear of self-expression. Based on these data, we assume that this factor may occur in certain life situations of students with SEN, and maybe a leading factor over other emotions. This is a group of subjects who have difficulties in communicating information about themselves to others, freely express their desires in words, actions, due to the presence of an internal barrier.28\% of the subjects have no psychoemotional difficulties in self-expression. At the same time, the fear of non-compliance with the expectations of others is added here, the increased level of which is revealed in $44 \%$ and $8 \%$ of the subjects have a high level. That is, perhaps, students with the SEN are not disclosed also because they are afraid to worry about how "adequately" and "unmistakably" they will look in the eyes of their peers. And this result also suggests that this group is focused on the opinion and assessment of others and they need psychological, pedagogical, social support. $52 \%$ of subjects have no fear of not meeting the expectations of others. For this group, their own ideas and assessment of reality are more important, they are more focused on their values and interests. $4 \%$ of respondents have a strong, and $34 \%-$ less strong fear of testing their knowledge. This group of respondents is characterised by anxiety in the situation of checking their capabilities and achievements.

On the contrary, $60 \%$ of the subjects in the situation of knowledge testing do not have feelings of anxiety and are favourable to the assessment of their knowledge and skills. In $24 \%$ of subjects elevated and
$8 \%$ of subjects a high level of negative emotional feelings expressed in a state of anxiety in the relationship with teachers.68\% of the examinees have confidence in their abilities, and fear in the relationship with the teacher has no place for them. $20 \%$ of the surveyed students have an elevated level, and $16 \%$ of the subjects have a high level of low physiological resistance to stress. In the behaviour of these subjects can be observed low adaptability to problem-stressful situations. $64 \%$ of the subjects had normal physiological resistance to stress, which suggests that the possible conditions for the emergence of anxiety are not physiological, but social. Thus, according to the results of the method of studying the level and nature of anxiety by Phillips, we can say that this group of subjects is characterised mainly by an average level of anxiety, except some respondents who have a tendency to increased and high levels of anxiety for individual factors.

\section{The data obtained are shown in Diagram 2.}

Following the methodology that we used in our work is a method $\mathrm{H}$ d Silberer in the adaptation of $\mathrm{Y}$. $\mathrm{L}$. Hanina. This psychometric technique is a reliable, informative and adequate way of self-assessment of the level of anxiety both at the moment (situational anxiety (SA) as a condition) and anxiety disorders as a stable characteristic of a person (personal anxiety (PA), reflecting the tendency of an individual to perceive a large range of situations as threatening, potentially dangerous and respond to them as a state of anxiety. This technique is presented in the form of a questionnaire of 40 questions. Analyzing the data obtained by the results of the Spielberger questionnaire, we obtained a division of our sample into two groups according to the severity of personal

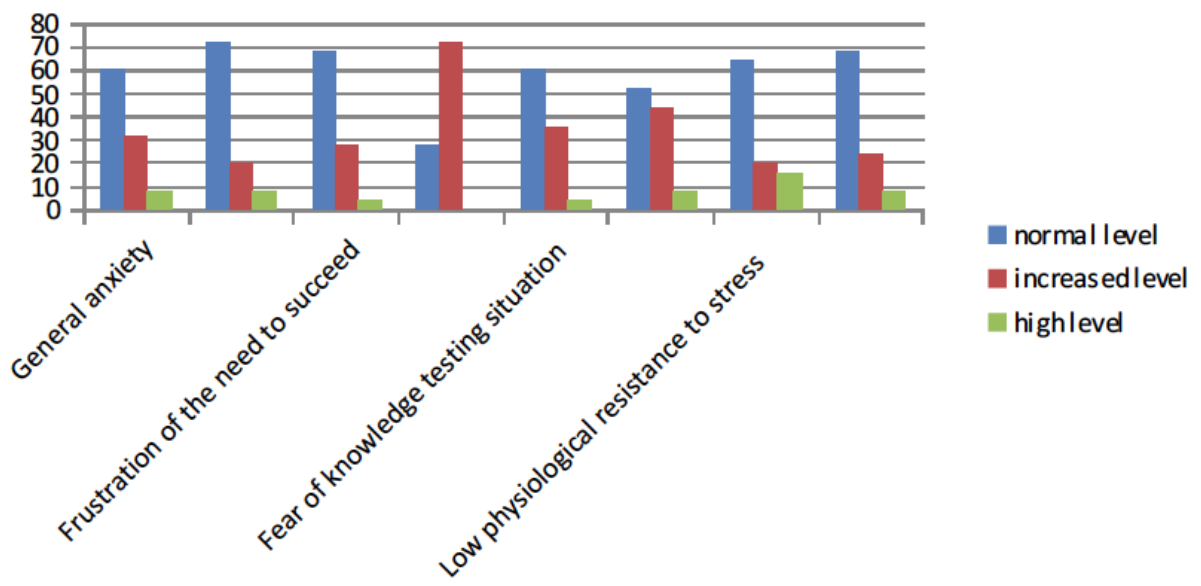

Diagram 2: Level and nature of anxiety associated with learning activities. 


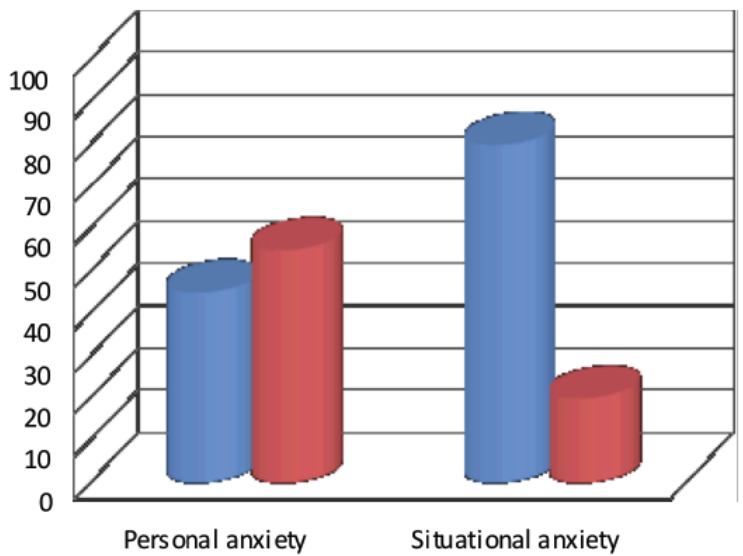

Moderate level of anxiety

- High level of anxi ety

Diagram 3: Levels of personal and situational anxiety.

anxiety (PA): $45 \%$ of respondents with a moderate level of personal anxiety (from 31 to 44 points), $55 \%$ of respondents with a high level of personal anxiety (more than 45 points). Situational anxiety (SA): $74 \%$ of respondents showed moderate anxiety, $26 \%$ of respondents had a high level of situational anxiety. Thus, students with special educational needs of our University, at the beginning of the school year, have a moderate level of LT in $45 \%$ and SA in $74 \%$ of the surveyed. In General, the group has a moderate level of situational anxiety and a high level of personal anxiety. This suggests that the state of anxiety in more than $70 \%$ of the subjects, more or less safe, perhaps there are moments when there are discomfort and anxiety, not explained by the conditions. $30 \%$ of the surveyed were highly anxious students who are prone to focus on adverse emotions, faced with various restrictions experiencing despair, tend to perceive a threat to their self-esteem and livelihoods in a wide range of situations and respond to a pronounced state of anxiety. The data obtained are shown in Diagram 3.

\section{DISCUSSION}

Thus, the hypothesis of our study was partially confirmed. Using the results of the study, we can conclude that increased and high levels of anxiety in students with SEN may occur due to the following circumstances:

1. The fear to express their capabilities, fear the possibility of being wrong, the presence of uncertainty and fear manifested in pointless fear, as a consequence of sinistrality.

2. The situation of evaluation and verification in the learning process and the presentation of high demands by the teacher. The basis in this case for the occurrence of anxiety, we believe, perhaps, health indicators associated with the manifestations of the disease, as well as insufficiently formed self-regulation of the individual in a particular, exciting situation.

3. Socio-psychological conditions (stressors): information overload, competition (competition), waiting for a negative assessment.

In the course of the study, the presence of increased and high levels of anxiety was revealed in more than $30 \%$ of the subjects. Also, there were high rates and individual factors, almost all subjects, it is, for example, fear of self-expression, fear of noncompliance with the expectations of others, low physiological resistance to stress. As we see, according to the results of the study, a high percentage on the scale of "General anxiety" have $34 \%$ of the subjects (10 people). Such indicators show that these students tend to experience the anxiety of varying degrees of intensity, while in the learning process: in the process of learning, testing and evaluation of knowledge, as well as in the process of communication and interaction with teachers and peers. For example, $72 \%$ of subjects have an increased level of fear of selfexpression. In $44 \%$ of subjects there is an increased anxiety of fear not to meet the expectations of others. In $36 \%$ of subjects there is increased anxiety in situations of knowledge testing. Thus, according to the results of the first technique, it can be said that the group of subjects is characterised mainly by an average level of anxiety and only some subjects are predisposed to an increased and high level of anxiety for certain factors. The results of the second method showed that in the group of subjects there is an increased level of personal anxiety, and situational anxiety is within the average level. 


\section{CONCLUSION}

Summing up our work, we can say that in the psycho-emotional state and, accordingly, in the manifestation of anxiety in students with special educational needs in the learning process involves a range of factors (age, socio-psychological, physiological obstacles), causing behavioural reactions frustrating character. And that is why, due to the mismatch of opportunities and priorities, there is an increase in the normative level of anxiety. Psychoprophylaxis to overcome anxiety in students with special educational needs should be personally oriented and focus on those personal characteristics and factors of society that are possible causes of anxiety. The work should be oriented between all subjects of the educational space and comprehensively carried out by age, sex, individual characteristics of the individual. At the student stage, we should pay attention, in our opinion, to the strengthening of the "Iconcept" of the individual, her attitude to herself, the formation of adequate self-esteem and effective resolution of internal and external conflicts arising from her. And also, a significant role is played by providing the individual with the necessary set of tools and methods of action and behaviour in situations important for him, the development of an individual's effective model of behaviour.
On the basis of the identified types of anxiety during the experiment, we have developed a system of corrective, rehabilitation measures aimed at the formation of an adequate level of anxiety and strengthening the emotional well-being of students with special educational needs of our University.

\section{REFERENCES}

[1] Astapov M. Actual problems of modern psychology-the problem of anxiety. Reader. Astapov V. M. Moscow 2008; pp. 107-110.

[2] Vygotsky LS. The Fundamentals of defectology. Textbooks for universities. Special literatures), St. Petersburg: DOE, 2003; p. 16

[3] Kostina LM. Methods of diagnostics of anxiety. Kostina L. M. -SPb.: Speech 2005; p. 198.

[4] Luchkov VV, Pevzner MS. Value of L. S. Vygotsky's theory for psychology and defectology (idem). Vestnik Moskovskogo universiteta. Episode 14. Psychology 1981; 4: 60-70.

[5] The methodology for the study of the level and nature of anxiety Phillips azps.ru/tests/tests philips.htmlhttps: 2018; [Electron.resource]

[6] The methodology for the study of the level and nature of anxiety spielberger $\mathrm{H}$, in the adaptation of $\mathrm{Y}$. L. Hanina. www.gurutestov.ru/test/168/ $2018 \mathrm{~g}$. [Electron.resource]

[7] Parishioners AM. Anxiety in children and adolescents: psychological nature and age dynamics. - M: Moscow psychology-social Institute; Voronezh: Publishing house NPO "MODEK", 2000; 304.

Received on 25-10-2018

\section{DOI: https://doi.org/10.6000/2292-2598.2018.06.04.2}

(c) 2018 Nurgul et al.; Licensee Lifescience Global.

This is an open access article licensed under the terms of the Creative Commons Attribution Non-Commercial License (http://creativecommons.org/licenses/by-nc/3.0/) which permits unrestricted, non-commercial use, distribution and reproduction in any medium, provided the work is properly cited. 